\title{
Cyclic Ether Carcinogen
}

National Cancer Institute

\section{Source}

National Cancer Institute. Cyclic Ether Carcinogen. NCI Thesaurus. Code C45187.

A cyclic compound in which two carbon atoms are linked through an oxygen atom and exposure to these compounds can increase the risk of cancer in humans. ( $\mathrm{NCI05)}$ 